\title{
Hypoglycemic Effect of Yacon Tuber Extract and Its Constituent, Chlorogenic Acid, in Streptozotocin-Induced Diabetic Rats
}

\author{
Jeong Sook Park ${ }^{1}$, Jae Sik YANG ${ }^{1}$, Bang Yeon Hwang ${ }^{1}$, Bong Kyu Yoo ${ }^{2}$, and Kun HaN ${ }^{1, *}$ \\ ${ }^{1}$ College of Pharmacy, Chungbuk National University, Cheongju 361-763, ${ }^{2}$ College of Pharmacy, \\ Yeungnam University, Deagu 705-717, Republic of Korea
}

(Received May 11, 2009; Revised June 15, 2009; Accepted June 19, 2009)

\begin{abstract}
Smallanthus sonchifolius (Yacon, Asteraceae) was originally cultivated in South America and used in food and traditional medicine by Andean inhabitants. Yacon is potentially beneficial for the management of diabetes and is composed of fructooligosaccharides, proteins, minerals and phenolic compounds. The aim of this study was to investigate the hypoglycemic effect of Yacon tuber extract (YTE) and its constituent, chlorogenic acid (CGA), in streptozotocin (STZ)-induced diabetic rats. In this study, a HPLC method was developed for simultaneous determination of major active phenolic components, CGA and caffeic acid in YTE. We investigated the hypoglycemic effect of YTE and CGA in STZ-induced diabetic rats and studied glucose tolerance test (GTT). The effect of orally administered multiple doses of YTE and CGA on plasma biochemical parameters was examined using diabetic rats. We also measured free radical scavenging activity by the 2,2-diphenyl-1-picrylhydrazyl (DPPH) assay. Oral administration of YTE $(200 \mathrm{mg} / \mathrm{kg})$ and CGA $(10 \mathrm{mg} / \mathrm{kg})$ for 6 weeks produced a significant hypoglycemic effect in STZ-induced diabetic rats. YTE and CGA-treated groups exhibited significantly decreased plasma glucose surge during the GTT. Total cholesterol (TC) and triglyceride (TG) concentrations were significantly decreased by $33 \%$ and $49 \%$, respectively, in YTE-treated rats. TC and TG concentrations were also significantly decreased by $26 \%$ and $41 \%$, respectively, in CGA-treated rats. In the DPPH assay, free radical scavenging activity of CGA was similar to that of vitamin E, a positive control. This study suggests that YTE and its constituent, CGA, may be a useful option for management of hyperglycemia and diabetic nephropathy.
\end{abstract}

Keywords: Yacon, Chlorogenic acid, Diabetes, Streptozotocin, DPPH

\section{INTRODUCTION}

Diabetes mellitus is a metabolic disease characterized by hyperglycemia resulting from defects in insulin secretion, action or both. It is a leading cause of human death and afflicts an estimated $6 \%$ of the adult population in industrialized nations. The worldwide incidence of diabetes mellitus is expected to continue to grow, potentially reaching 200-300 million cases in 2010 (Amos et al., 1997). Chronic hyperglycemia of diabetes is associated with long-term damage, dysfunction, and the eventual failure of organs, especially the eyes, kidneys, nerves, heart, and blood vessels.

To date, there are several groups of oral hypoglycemic

${ }^{*}$ Corresponding author

Tel: +82-43-261-2820 Fax: +82-43-273-3350

E-mail: khan@chungbuk.ac.kr agents for clinical use that have characteristic side effect profiles (Rottlaender et al., 2007; Bruijstens et al., 2008; Byron et al., 2008). Management of diabetes without any side effects remains a challenge to the medical system. This has led to increasing demand for natural products with antidiabetic activity and fewer side effects. A number of investigations have confirmed the efficacy of many of these preparations, some of which are remarkably effective (Marles et al., 1995; Kesari et al., 2006; Kesari et al., 2007).

Yacon (Smallanthus sonchifolius, Asteraceae) is a perennial herb 1.5-3 $\mathrm{m}$ tall with a root system composed of 420 edible fleshy tuberous storage roots. The aerial stems, densely pubescent green to purplish, are cylindrical or subangular and hollow at maturity, with only a few branches in most clones. Yacon tuber is composed of water, fructooligosaccharides, proteins, minerals and polyphenols 
(Aybar et al., 2001; Lachman et al., 2003). Yacon, considered a 'fruit' by the early Andean inhabitants, has a relatively low energy value despite its juiciness and sweet taste. Yacon has been consumed commonly by diabetics and persons suffering from digestive disorders (Pedreschi et al., 2002). Chlorogenic acid (3-O-caffeoyl-D-quinic acid, CGA) is an ester formed between caffeic acid and quinic acid, and is one of the major polyphenolic compounds in Yacon.

Many studies have suggested that polyphenols, especially CGA, have hypoglycemic effects. CGA has been shown to inhibit glucose-glucose-6-phosphatase, the enzyme that catalyzes the final step of glycogenolysis and gluconeogenesis (Arion et al., 1998; Herling et al., 1998).

The aim of this study was to investigate the hypoglycemic effect of YTE and its constituent, CGA, in STZ-induced diabetic rats. The effects of YTE and CGA on antioxidant activity and NO inhibition were studied.

\section{MATERIALS AND METHODS}

\section{Preparation of Yacon tuber extract (YTE)}

Plant materials were purchased from Bonghwa (Gyeongbuk, Korea) and authenticated by Dr. Hwang, a botany professor at the College of Pharmacy, Chungbuk National University (Cheongju, Korea). Yacon tuber was washed with water and dried under sunlight. For extraction, dried Yacon tuber was soaked overnight in 50\% ethanol at room temperature. After soaking, the extract was sonicated three times for 5 hours at $60^{\circ} \mathrm{C}$ and then filtered through filter paper (Whatman No.1). The extract was concentrated in a rotary evaporator under reduced pressure and freeze-dried to a powder. YTE was dissolved in water at a concentration of $100 \mathrm{mg} / \mathrm{ml}$ for further use.

\section{HPLC analysis of phenolic compounds in YTE}

Phenolic compounds were analyzed with Hitachi HPLC system equipped with pumps (L-6000, L-6200), UV-VIS detector (L-4200) and chromato-integrator (D-2500). The Kromasil $\mathrm{C}_{18}$ column $(250 \times 4.6 \mathrm{~mm})$ was used. The binary mobile phase consisted of phase $\mathrm{A}, 10 \% \mathrm{v} / \mathrm{v} \mathrm{CH}_{3} \mathrm{CN}$ in water and $0.05 \% \mathrm{v} / \mathrm{v}$ acetic acid, and phase $\mathrm{B}, 90 \% \mathrm{v} / \mathrm{v}$ $\mathrm{CH}_{3} \mathrm{CN}$ in water and $0.05 \% \mathrm{v} / \mathrm{v}$ acetic acid. Gradient was achieved as follows: $0.0 \mathrm{~min} 100 \% \mathrm{~A}$, flow rate $0.5 \mathrm{ml} / \mathrm{min}$, $39.0 \mathrm{~min} 100 \% \mathrm{~B}$, flow rate $0.5 \mathrm{ml} / \mathrm{min}, 40.0 \mathrm{~min} 100 \% \mathrm{~B}$, flow rate $1.0 \mathrm{ml} / \mathrm{min}, 41.0 \mathrm{~min} 100 \% \mathrm{~A}$, flow rate 1.0 $\mathrm{ml} / \mathrm{min}, 46.0 \mathrm{~min} 100 \% \mathrm{~A}$, flow rate $1.0 \mathrm{ml} / \mathrm{min}, 47.0 \mathrm{~min}$ $100 \% \mathrm{~A}$, flow rate $0.5 \mathrm{ml} / \mathrm{min}$. The injection volume was 50 $\mu \mathrm{l}$. Detection was performed at a wavelength of $236 \mathrm{~nm}$.

\section{Induction of diabetes}

Six-week-old male Sprague-Dawley rats were purchased from Samtako (Gyeonggi, Korea) and acclimated with free access to food and water for at least 1 week. The animals were maintained under controlled conditions [temperature: $23 \pm 1^{\circ} \mathrm{C}$; relative humidity: $55 \pm 10 \%$; and lighting: 12 hours/day]. Diabetes was induced by the administration of streptozotocin (STZ) $60 \mathrm{mg} / \mathrm{kg}$ (i.p.) dissolved in $10 \mathrm{mM}$ sodium citrate buffer ( $\mathrm{pH} 4.5)$; the control group received only citrate buffer. Diabetes was achieved within 24 hours in the majority of animals. Only animals with plasma glucose levels of $250-400 \mathrm{mg} / \mathrm{dl} 7$ days after STZ treatment were included in the study. To determine the effects of YTE and CGA, rats were divided into four groups: 1) control group; 2) STZ group; 3) YTE (200 $\mathrm{mg} / \mathrm{kg})+$ STZ group; 4) CGA (10 mg/kg) + STZ group. Rats were administered YTE or CGA in distilled water once a day for 6 weeks by oral administration. The control group was administered purified water alone for the same period. The amount of YTE or CGA administered was determined from preliminary studies (Park et al., 2008).

\section{Glucose tolerance test (GTT)}

After administering YTE or CGA for 5 weeks to STZ-induced diabetic rats, the rats were used for GTT. Rats were fasted for 12-15 hours before the GT test. On the test day, purified water (control), YTE or CGA solution was orally administered to each group. Thirty minutes later, $50 \%$ glucose solution was administered at a dose of $2 \mathrm{~g} / \mathrm{kg}$ (i.p.). Blood samples were taken from the tail vein at 0 (just before glucose administration), 1, 2, 3, 4, 5 and 6 hours for the measurement of blood glucose. Glucose levels in the blood samples were measured by ACCU-CHEK GO (Roche).

\section{Measurement of plasma glucose level, body weight, food and drinking water intake}

Blood samples were obtained from the tail vein and the glucose level was measured as previously described. Body weight was measured every week for 6 weeks. Food and drinking water were available ad libitum and measured daily.

\section{Collection of blood and tissue samples}

At the end of the experimental period, animals were fasted for 12 hours prior to sacrifice. Rats were anesthetized with ether and blood samples were collected via the abdominal aorta. Plasma was separated by centrifugation $(3,000 \mathrm{rpm})$ at $4^{\circ} \mathrm{C}$ for $15 \mathrm{~min}$. Liver and kidney were excised and weighed, and the weights of organs 
were calculated as the organ weight per $100 \mathrm{~g}$ of body weight. After measurement, organs were immediately frozen and stored at $-70^{\circ} \mathrm{C}$ until further analysis.

\section{Estimation of biochemical parameters in plasma}

The levels of glucose, total cholesterol (TC), triglyceride (TG), creatinine and blood urea nitrogen (BUN) in the plas$\mathrm{ma}$, as well as the activities of aspartate aminotransferase (AST) and alanine aminotransferase (ALT), were determined with the automated biochemistry analyzer (Hitachi-747, Hitachi Medical Co., Tokyo, Japan).

\section{DPPH free radical scavenging activity}

DPPH assay was performed with a slight modification of Brand-Williams's method (1995). DPPH solution was prepared at a concentration of $2 \times 10^{-4} \mathrm{~mol} / \mathrm{L}$ in methanol. During the test, $2 \mathrm{ml}$ of sample was mixed with $2 \mathrm{ml}$ of DPPH solution. The test tube was capped after nitrogen bubbling and placed in the dark. After standing for $60 \mathrm{~min}$ at $20^{\circ} \mathrm{C}$, the absorbance was measured at $517 \mathrm{~nm}$ by a UV/VIS spectrophotometer. All samples were prepared in triplicate, and vitamin $\mathrm{E}$ was the positive control.

\section{Cell culture}

RAW 264.7 cells were purchased from ATCC (American Type Culture Collection, Manassas, VA, USA). The cells were grown in Dulbecco's modified Eagle's media supplemented with 10\% FBS, benzylpenicillin potassium (143 $\mathrm{U} / \mathrm{ml})$ and streptomycin sulfate $(100 \mu \mathrm{g} / \mathrm{ml})$ at $37^{\circ} \mathrm{C}$ in a $5 \%$ $\mathrm{CO}_{2}$ atmosphere.

\section{Determination of NO production}

RAW 264.7 cells were pretreated with different concentrations $(25,50,100 \mu \mathrm{g} / \mathrm{ml})$ of YTE or CGA for $2 \mathrm{hrs}$ and then stimulated with LPS $(1 \mu \mathrm{g} / \mathrm{ml})$ for $24 \mathrm{hrs}$. Amounts of nitrite were measured by Archer's method (1993). In brief, aliquots $(100 \mu \mathrm{l})$ of the culture media were reacted with 1:1 mixture $(100 \mu \mathrm{l})$ of $1 \%$ sulfanilamide and $0.1 \% \mathrm{~N}-(1-$ naphthyl)ethylenediamine, and the absorbance values were measured at $540 \mathrm{~nm}$.

\section{Statistical analysis}

The data was analyzed using one-way ANOVA followed by Dunnett's test as a post hoc test with SigmaStat ${ }^{\mathbb{R}}$. Differences were considered statistically significant at the ${ }^{*} p<0.05$ and ${ }^{* *} p<0.01$ levels, as indicated.

\section{RESULTS}

\section{HPLC analysis of phenolic compounds in YTE}

Simonovska et al.(2003) reported that the crude extract of Yacon leaves contains phenolic compounds, i.e., CGA, ferulic acid and caffeic acid, based on HPLC/MS data. In the present study, CGA was found to be the major component of YTE (Fig. 1). The amount of crude extract obtained from Yacon tubers (10 g) using 50\% ethanol was $7.31 \mathrm{~g}$, and the amount of CGA obtained from $1 \mathrm{mg}$ of YTE was $2.83 \mu \mathrm{g}$.

\section{Effect of YTE and CGA on streptozotocin (STZ)-induced diabetic rats}

In STZ-induced diabetic rats, plasma glucose levels were about three times higher than those in normal rats (Fig. 2). The administration of YTE $(200 \mathrm{mg} / \mathrm{kg})$ or CGA $(10 \mathrm{mg} / \mathrm{kg})$ to diabetic rats for 6 weeks significantly decreased blood glucose levels compared with diabetic controls from week 4 until the end of the experimental treatment period.
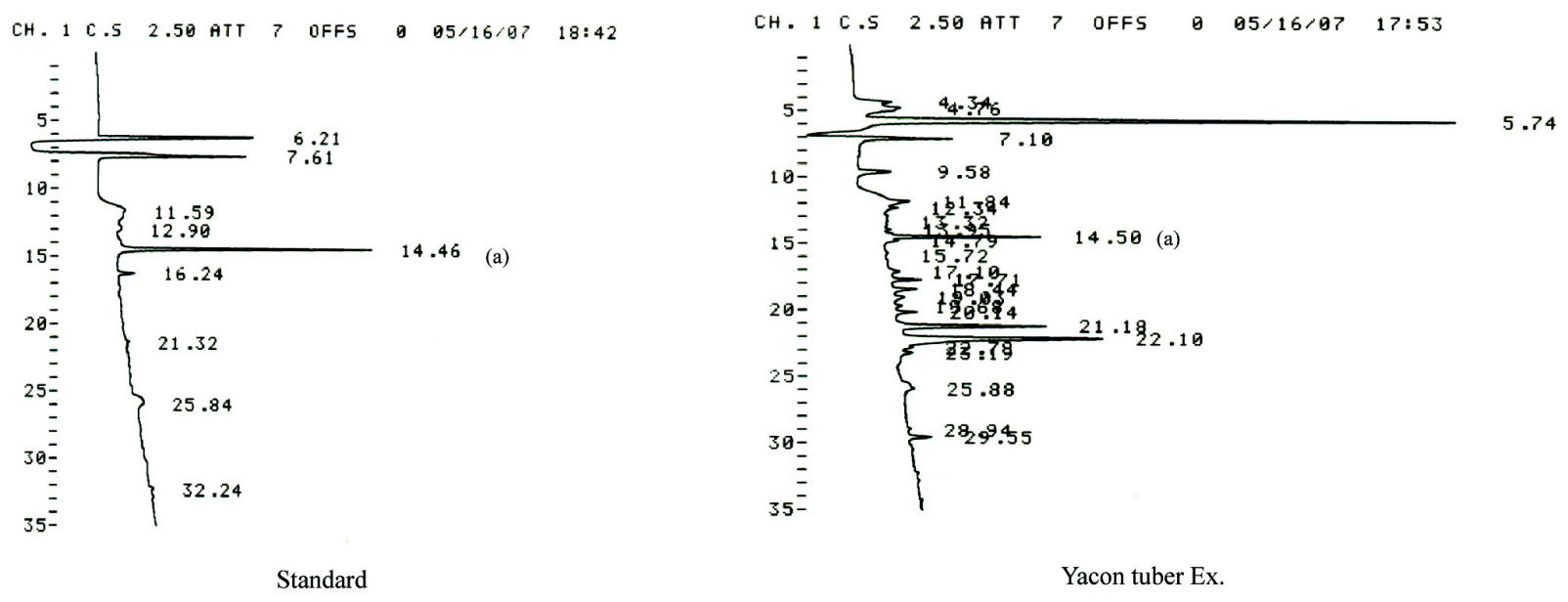

Fig. 1. HPLC chromatogram of standard and YTE. (a) chlorogenic acid. 


\section{Effect of YTE and CGA on GTT}

The plasma glucose levels of diabetic rats peaked at 1 hour after the intraperitoneal administration of glucose (Fig. 3). The administration of YTE or CGA decreased the plasma glucose levels, which were significantly lower than those of the STZ-treated control group at 1-6 $\mathrm{h}$ after glucose administration. Our results revealed that YTE and CGA produced glucose tolerance.

\section{Body weight, food intake, drinking water intake and organ weights}

The changes of body weight, food intake, drinking water intake and organ weights in STZ-induced diabetic rats and

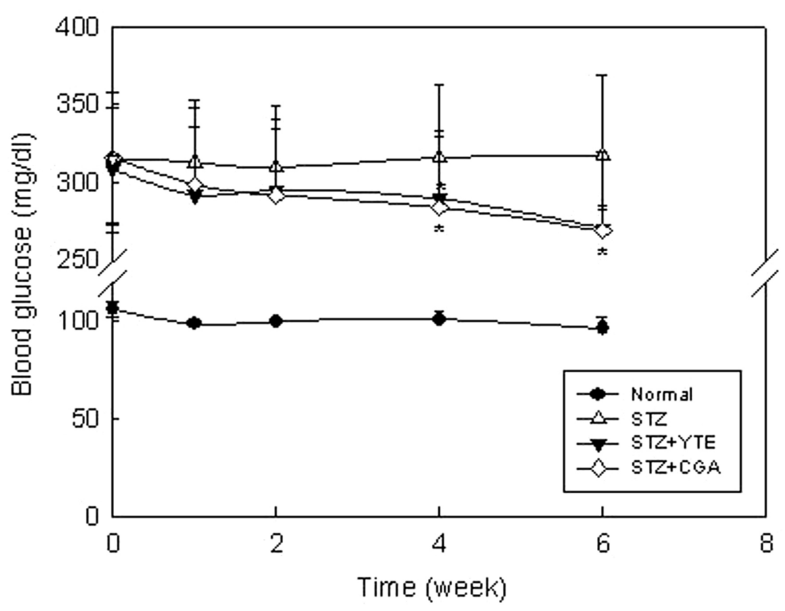

Fig. 2. Effect of YTE and CGA on fasting plasma glucose levels in STZ-induced diabetic rats. Data are presented as means \pm $\mathrm{SD}(\mathrm{n}=7-8)$. *Significantly different from the STZ-treated control (ANOVA test, ${ }^{*} p<0.05$ ). non-diabetic rats are shown in Tables $1 \& 2$. At the end of the study, STZ-induced diabetic rats showed lower body weight than the normal control group (Table I). However, no significant changes in body weight, food and drinking water intake were observed in the positive control group and in the YTE- or CGA-treated group after STZ-induced diabetes (Table I). There was no significant change in organ weights among STZ-induced diabetic rats and YTE- or CGA-treated group after STZ-induced diabetes (Table II).

\section{Estimation of biochemical parameters in plasma}

Table III shows the effects of 6-week YTE or CGA administration on plasma biochemical parameters. There

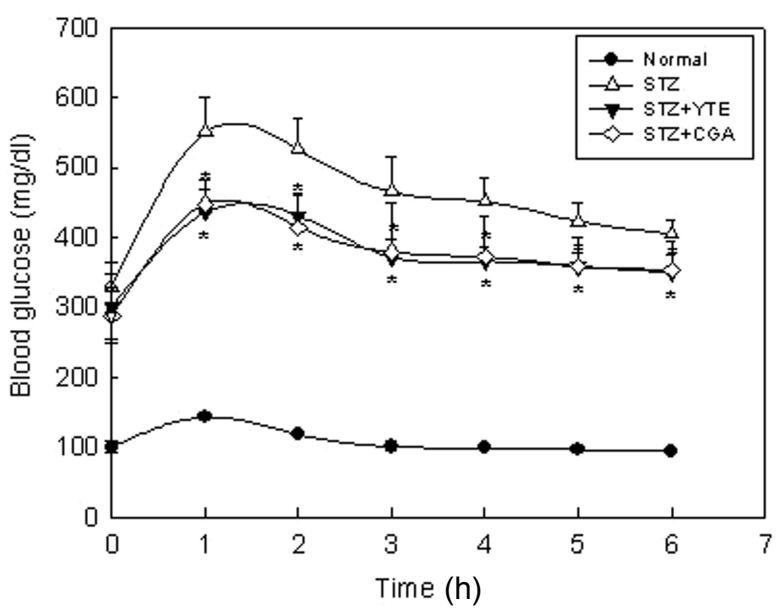

Fig. 3. Effect of YTE and CGA on glucose tolerance test in STZ-induced diabetic rats. Data are presented as means \pm SD $(n=7-8)$. *Significantly different from the STZ-treated control (ANOVA test, ${ }^{*} p<0.05$ ).

Table I. Body weight, food intake and drinking water intake during 6-week period

\begin{tabular}{lccr}
\hline & Treatment group & Body weight $(\mathrm{g})$ & Food intake $(\mathrm{g} / \mathrm{rat} / \mathrm{day})$ \\
\hline & Initial & Final & Water intake (ml/rat/day) \\
Normal & $260.00 \pm 10.95$ & $408.33 \pm 22.29$ & $13.41 \pm 2.41$ \\
STZ & $168.75 \pm 19.59$ & $210.00 \pm 32.07$ & $18.47 \pm 3.45$ \\
STZ+YTE & $156.67 \pm 13.23$ & $203.33 \pm 23.45$ & $17.69 \pm 2.87$ \\
STZ+ CGA & $161.11 \pm 10.54$ & $201.11 \pm 22.05$ & $16.73 \pm 3.02$ \\
\hline
\end{tabular}

Data are presented as means $\pm S D(n=7-8)$.

Table II. Organ weights in normal and diabetic rats

\begin{tabular}{lcccc}
\hline & Kidney $(\mathrm{g})$ & Liver $(\mathrm{g})$ & Kidney $/ 100 \mathrm{~g}$ & Liver $/ 100 \mathrm{~g}$ \\
\hline Control & $2.58 \pm 0.12$ & $11.89 \pm 0.62$ & $0.58 \pm 0.03$ & $2.66 \pm 0.11$ \\
STZ & $2.29 \pm 0.32$ & $7.68 \pm 1.66$ & $1.15 \pm 0.20$ & $3.77 \pm 0.29$ \\
STZ+YTE & $2.33 \pm 0.17$ & $7.42 \pm 0.84$ & $1.23 \pm 0.12$ & $3.90 \pm 0.27$ \\
STZ+ CGA & $2.29 \pm 0.12$ & $7.72 \pm 0.74$ & $1.17 \pm 0.12$ & $3.93 \pm 0.29$ \\
\hline
\end{tabular}

Data are presented as means $\pm S D(n=7-8)$. 
Jeong Sook Park et al.

Table III. Effects of YTE and CGA on various biochemical parameters in rat plasma

\begin{tabular}{lcccc}
\hline & Control & STZ & STZ+YTE & STZ+CGA \\
\hline Total cholesterol $(\mathrm{mg} / \mathrm{dl})$ & $76.60 \pm 21.82$ & $93.10 \pm 33.66$ & $62.44 \pm 9.78^{\mathrm{a}}$ & $68.96 \pm 18.13$ \\
Triglyceride $(\mathrm{mg} / \mathrm{dl})$ & $79.00 \pm 18.97$ & $144.78 \pm 48.04$ & $74.87 \pm 27.79^{\mathrm{a}}$ & $85.43 \pm 39.02^{\mathrm{a}}$ \\
Creatinine $(\mathrm{mg} / \mathrm{dl})$ & $0.30 \pm 0.10$ & $0.38 \pm 0.08$ & $0.27 \pm 0.10^{\mathrm{a}}$ & $0.30 \pm 0.06^{\mathrm{a}}$ \\
BUN $(\mathrm{mg} / \mathrm{dl})$ & $15.03 \pm 3.70$ & $39.13 \pm 10.53$ & $34.09 \pm 8.60$ & $28.31 \pm 6.52^{\mathrm{a}}$ \\
AST $(\mathrm{IU} / \mathrm{L})$ & $211.13 \pm 69.45$ & $300.47 \pm 81.07$ & $289.81 \pm 153.46$ & $355.80 \pm 324.83$ \\
ALT (IU/L) & $40.60 \pm 10.98$ & $96.47 \pm 25.46$ & $114.53 \pm 56.64$ & $154.16 \pm 197.16$ \\
\hline
\end{tabular}

Data are presented as means \pm SD $(n=7-8)$. ${ }^{a}$ Significantly different from the STZ-treated control (ANOVA test, $\left.{ }^{a} p<0.05\right)$.

Table IV. DPPH free radical scavenging activity $\left(E_{50}\right)$ of $Y T E$ and CGA compared with vitamin $\mathrm{E}$ as a positive control

\begin{tabular}{lc}
\hline & $\mathrm{EC}_{50}(\mu \mathrm{g} / \mathrm{ml})$ \\
\hline YTE & 675.28 \\
CGA & 15.01 \\
Vitamin E & 29.17 \\
\hline
\end{tabular}

were significant changes in TC, TG, Creatinine, BUN, AST and ALT between normal and diabetic control groups. The administration of YTE or CGA after STZ-induced diabetes decreased TC and TG levels compared with those in the diabetic control group. Especially, TG level was decreased by 48.3 and $40.0 \%$ with YTE and CGA administration, respectively, compared with that in the diabetic control group. YTE or CGA administration also decreased creatinine and BUN levels compared with those in the diabetic control group. In contrast, no significant differences were observed in AST and ALT between the diabetic control group and YTE- or CGA-treated group.

\section{DPPH scavenging activity of YTE and CGA}

Table IV shows the DPPH scavenging activities of YTE, CGA and vitamin E. CGA exhibited higher DPPH scavenging activity than vitamin E, while YTE showed DPPH scavenging activity in proportion to the total phenolic compound content. The total phenolic compound content of YTE was $3.60 \%$.

\section{Determination of NO inhibition}

We examined the effect of YTE and CGA on LPS-stimulated NO release from RAW 264.7 cells by detecting nitrite concentrations in cell culture media. As shown in Fig. 4, YTE dose-dependently inhibited the production of NO in LPS-stimulated RAW 264.7 cells, while CGA slightly inhibited NO production.

\section{DISCUSSION AND CONCLUSION}

The administration of YTE or CGA for 6 weeks reduced

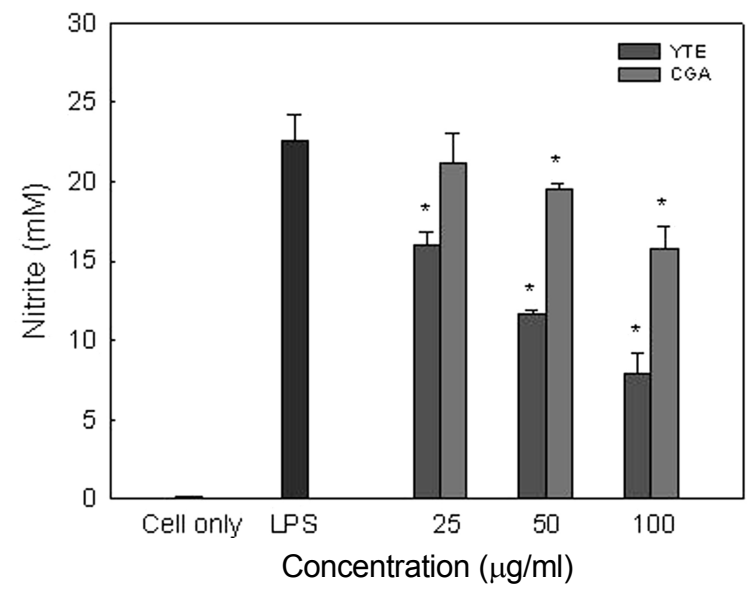

Fig. 4. The effects of YTE and chlorogenic acid on LPS-induced NO production in RAW 264.7 cells. Data are presented as means $\pm S D(n=6)$. *Significantly different from the control value (ANOVA test, ${ }^{*} p<0.05$ ).

diabetic manifestations. YTE or CGA significantly decreased blood glucose levels and the hyperglycemic peak during GTT in STZ-induced diabetic rats. They also significantly decreased TC and TG levels in plasma and improved the renal functional parameters, creatinine and BUN.

In the present study, we used STZ-induced diabetic rats. STZ, a diabetogenic agent, has a long history of use in diabetes research and is known to be specifically toxic to pancreatic $\beta$-cells. STZ is thought to release nitric oxide (NO) and oxygen free radicals during its metabolism (Takasu et al., 1991; Corbett et al., 1993; Lindsay et al., 1995; Wu, 1995; Tiedge et al., 1997). Recent studies suggest that oxygen free radicals or NO mediate the deleterious effects of STZ on $\beta$-cell dysfunction and destruction (Corbett \& McDaniel, 1992; Ho et al., 2000). However, the biomedical mechanisms that mediate the detrimental effect of STZ remain elusive.

Diabetes constitutes multiple sources of free radicals, starting very early in the disease process and worsening over the course of disease. Hyperglycemia generates oxida- 
tive stress and reduces antioxidant potential (Wiernsperger, 2003). CGA has been reported to suppress the N-nitrosating reaction and inhibit glucose 6-phosphatase, which may be a significant factor in the abnormal diabetic state. Moreover, preventive effects of CGA in the oxidation, lipid peroxidation and formation of hydroxyl free radical have been reported (Risch et al., 1988; Iwahashi et al., 1990; Ohnishi et al., 1994; Kono et al., 1995, 1997; Arion et al., 1998). In this study, CGA significantly decreased blood glucose levels and had similar antioxidant activity $\left(\mathrm{EC}_{50}\right.$ $17.8 \mu \mathrm{g} / \mathrm{ml})$ to vitamin $\mathrm{E}\left(\mathrm{EC}_{50} 13.7 \mu \mathrm{g} / \mathrm{ml}\right)$ as a positive control. YTE also exhibited DPPH scavenging activity in proportion to its total phenolic compound content. CGA and YTE improved the TC and TG levels in plasma.

$\mathrm{NO}$ is produced by the oxidation of L-arginine to L-citruline by nitric oxide synthase, and excess $N O$ generated in cells may inhibit mitochondrial metabolism, protein modification and DNA cleavage, any one of which could lead to insulin secretion impairment and $\beta$-cell death (Stadler et al., 1991; Kaneto et al., 1995; Eizirik et al., 1996). In this study, YTE inhibited the production of NO in LPS-stimulated RAW 264.7 cells, while CGA slightly inhibited NO production. Accordingly, we believe that the hypoglycemic effects of YTE and CGA are due to their antioxidant effects rather than $\mathrm{NO}$ inhibition. In conclusion, we propose that YTE containing CGA as an active compound may be useful for management of hyperglycemia.

\section{ACKNOWLEDGMENTS}

This work was supported by the Regional Research Center Program of the Korean Ministry of Education \& Human Resources Development.

\section{REFERENCES}

Amos, A. F., McCarty, D. J. and Zimmet, P. (1997). The rising global burden of diabetes and its complications: estimates and projections by 2010. Diabet. Med. 14(Suppl 5), S1-85.

Archer, S. (1993). Measurement of nitric oxide in biological models. FASEB J. 7, 349-360.

Arion, W. J., Canfield, W. K., Ramos, F. C., Schindler, P. W. Burger, H. J., Hemmerle, H., Schubert, G., Below, P. and Herling, A. W. (1998). Chlorogenic acid and hydroxynitrobenzaldehyde: new inhibitors of hepatic glucose-6-phosphatase. Arch. Biochem. Biophys. 339, 315-332.

Aybar, M. J., Riera, A. N. S., Grau, A. and Sanchez, S. S. (2001). Hypoglycemic effect of the water extract of Smallanthus sonchifolius (Yacon) leaves in normal and diabetic rats. J. Ethnopharm. 74, 125-132.

Brand-Williams, W. (1995). Use a free radical method to evaluate antioxidative activity. Food Sci. Technol. 28, 25-30.
Bruijstens, L. A., van Luin, M., Buscher-Jungerhans, P. M. M. and Bosch, F. H. (2008). Reality of severe metformin-induced lactic acidosis in the absence of chronic renal impairment. Neth. J. Med. 66, 185-190.

Byron, J. H., Krupa, B. D. and Dima, D. (2008). Pramlintide, the synthetic analogue of amylin: physiology, pathophysiology, and effects on glycemic control, body weight, and selected biomarkers of vascular risk. Vasc. Health Risk Manag. 4 355-362.

Corbett, J. A. and McDaniel, M. L. (1992). Does nitric oxide mediate autoimmune destruction of $\beta$-cells? Possible therapeutic interventions in IDDM. Diabetes. 41, 897-903.

Corbett, J. A., Mikhael, A., Shimizu, J., Fredrick, K., Misko, T. P., McDaniel, M. L., Kanagawa, O. and Unanue, E. R. (1993). Nitric oxide production in islets from nonobese diabetic mice: aminoguanidine-sensitive and-resistant stages in the immunological diabetic process. Proc. Natl. Acad. Sci. 90, 8992-8995.

Eizirik, D. L., Delaney, C. A., Green, M. H., Cunningham, J. M., Thorpe, J. R., Pipeleers, D. G., Hellerstrom, C. and Green, I. C. (1996). Nitric oxide donors decrease the function and survival of human pancreatic islets. Mol. Cell Endocrinol. 118, 71-83.

Herling, A. W., Burger, H. J., Schwab, D., Hemmerle, H., Below, P. and Schubert, G. (1998). Pharmacodynamic profile of a novel inhibitor of the glucose-6-phosphatase system. Am. J. Physiol. 274, G1087-G1093.

Ho, E., Chen, G. and Bray, T. M. (2000). Alpha-phenyl-tertbutylnitrone (PBN) inhibits NF $\kappa B$ activation offering protection against chemically induced diabetes. Free Radic. Biol. Med. 28, 604-614.

Iwahashi, H., Ishii, T., Sugata, R. and Kido, R. (1990). The effects of caffeic acid and its related catechols on hydroxyl radical formation by 3-hydroxyanthranilic acid, ferric chloride and hydrogen peroxide. Arch. Biochem. Biophys. 276, 242247.

Kaneto, H., Fujii, J., Seo, H. G., Suzuki, K., Matsuoka, T., Nakamura, M., Tatsumi, H., Yamasaki, Y., Kamada, T. and Taniguchi, N. (1995). Apoptotic cell death triggered by nitric oxide in pancreatic $\beta$-cells. Diabetes. 44, 733-738.

Kesari, A. N., Gupta, R. K. Singh, S. K., Diwakar, S. and Watai, G. (2006). Hypoglycemic and antihyperglycemic activity of Aegle marmelos seed extract in normal and diabetic rats. $J$. Ethnopharm. 107, 374-379.

Kesari, A. N., Kesari, S., Singh, S. K., Gupta, R. K. and Watai, G. (2007). Studies on the glycemic and lipidemic effect of Murraya koenigii in experimental animals. J. Ethnopharm. 112, 305-311.

Lachman, J., Fernandez, E. C. and Orsak, M. (2003). Yacon [Smallanthus sonchifolia (Poepp. et Endl.) H. Robinson] chemical composition and use - a review. Plant soil Environ. 49, 283-290.

Lindsay, R. M., Smith, W., Rossiter, S. P., Mclntyre, M. A., Williams, B. C. and Baird, J. D. (1995). N omega-nitro-Larginine methyl ester reduces the incidence of IDDM in BB/E rats. Diabetes. 44, 365-368.

Kono, Y., Kobayashi, K., Tagawa, S., Adachi, K., Ueda, A., Sawa, Y. and Shibata, H. (1997). Antioxidant activity of polyphenolics in diets: rate constants of reactions of chlorogenic acid and caffeic acid with reactive species of oxygen and nitrogen. Biochem. Biophys. 1335, 335-342. 
Kono, Y., Shibata, H., Kodama, Y. and Sawa, Y. (1995). Chlorogenic acid as a natural scavenger for hypochlorous acid. Biochem. J. 217, 972-978.

Marles, R. J. and Fransworth, N. R. (1995). Antidiabetic plants and their active constituents. Phytomedicine. 2, 137-189.

Ohnishi, M., Morishita, H., Iwahashi, H., Toda, S., Shirataki, Y., Kimura, M. and Kido, R. (1994). Inhibitory effects of chlorogenic acids on linoleic acid peroxidation and haemolysis. Phytochemistry. 36, 579-583.

Park, J. S., Hwang, S. Y., Hwang, B. Y. and Han, K. (2008). The spermatogenic effect of $50 \%$ ethanol extracts of Yacon and its ameliorative effect against 2,3,7,8-tetrachlorodibenzo$p$-dioxin induced testicular toxicity in the rat. J. Nat. Prod. 14, 73-80.

Pedreschi, R., Campos, D., Noratto, G., Chirinos, R. and Cisneros-Zevallos, L. A. (2002). Fermentation of fructooligosaccharides from Yacon. Preceeding of IFT Annual Meeting \& Food Expo, Anaheim, California. 15, 84-89.

Risch, B., Herrmann, K. and Lebensm, Z. (1988). Analysis of catechin and epicatechin by high-performance liquid chromatography after benzoylation. J. Chromatogr. A. 448, 291295.

Rottlaender, D., Michels, G., Erdmann, E. and Hoppe, U. C. (2007). Therapy with glitazones-a risk for cardiovascular disease? Dtsch. Med. Wochenschr. 132, 2629-2632.

Simonovska, B., Vovk, I., Andrenšek, S., Valentová, K. and Ulrichová, J. (2003). Investigation of phenolic acids in yacon (Smallanthus sonchifolius) leaves and tubers. J. Chromatogr. 1016, 89-98

Stadler, J., Billiar, T. R., Curran, R. D., Stuehr, D. J., Ochoa, J. B. and Simmons, R. L. (1991). Effect of exogenous and endogenous nitric oxide on mitochondrial respiration of rat hepatocytes. Am. J. Physiol. 260, C910-916.

Takasu, N., Asawa, T., Komiya, I., Nagasawa, Y. and Yamada, T. (1991). Alloxan-induced DNA strand breaks in pancreatic islets. Evidence for $\mathrm{H}_{2} \mathrm{O}_{2}$ as an intermediate. J. Biol. Chem. 266, 2112-2114.

Tiedge, M., Lortz, S., Drinkgern, J. and Lenzen, S. (1997). Relation between antioxidant enzyme gene expression and antioxidantative defense status of insulin-producing cells. Diabetes. 46, 1733-1742.

Wiernsperger, N. F. (2003). Oxidative stress as a therapeutic target in diabetes: revisiting the controversy. Diabetes. Metab. 29, 579-585.

Wu, G. (1995). Nitric oxide synthesis and the effect of aminoguanidine and NG-monomethyl-L-arginine on the onset of diabetes in the spontaneously diabetic BB rat. Diabetes. 44, 360-364. 